\title{
Sugar; tax and reformulation
}

\author{
Stephen Hancocks OBE \\ Editor-in-Chief
}

The BDJ Upfront section includes editorials, letters, news, book reviews and interviews. Please direct your correspondence to the News Editor,

Adrian O'Dowd at BDJNews@nature.com. Press releases or articles may be edited, and should include a colour photograph if possible.

$\mathrm{I}$ $\mathrm{n}$ an editorial last year I wrote with a sense of mock disgruntlement that as a profession we had been talking, teaching, raising awareness and warning of the dangers of sugar in relation to caries for decades but that no one had paid much attention. ${ }^{1}$ I continued that the situation had changed thanks to the growing problem of obesity which has made many more individuals, health professionals, health campaigners and most significantly politicians, sit up and take some notice. My tone of aggrievement was playful in that any support which improves the health of the population is very welcome, if long overdue.

To aid this, the BDA recently organised a day's symposium entitled 'Sugar and oral health Summit'. A host of eminent speakers and an audience of representatives from dental, medical and health-associated organisations with the common characteristic of being, as it were, steeped in sugar were treated to an occasion providing much on which to ponder. Several themes emerged and further reports will be forthcoming here and through the BDA. For me one of the most striking was the way in which the wider forces now joining in the battle against sugar are bringing to bear the lessons learnt from other health campaigns.

Tobacco is one example with which we are familiar as professionals as well as socially. The decline in smoking in the UK in recent years has been quite remarkable. A situation that I could never have envisaged even 15 years ago. As a profession we have embraced the notion of discussing tobacco cessation with our patients in a way that previously seemed unlikely and this has doubtless reinforced the general public opinion that smoking is bad for health with all its concomitant disadvantages, miseries and costs. But, importantly, the mood has been caught by successive governments who have imposed increasing levels of taxation on tobacco as well as introducing advertising bans, plain packaging and other barriers. Collectively this has unquestionably made a huge difference.
When mapped onto the sugar issue there is not a direct overlap for a variety of reasons. We might chose to smoke or not but we cannot effectively chose under normal circumstances not to eat and drink. Granted we can make healthy choices but these too are obscured by lack of information, understanding, complications of socioeconomic situation, lifestyle and, not least, motivation. However, if the sugar content of the food and drink that is available to us is dictated by the food manufacturing industry then even our careful tiptoeing between products is beset with complications.

This is where two glimmers of hope shone out from the Summit. Salt has been reduced substantially from processed food in recent years. Were you aware? I admit I was not. Yet this change brought about through evidence- actually noticed a difference? The value of this thin end of the wedge approach is that progressive levels of taxation and continued reduction in sugar content could gradually make a difference in the same way that tax on tobacco and reduction in salt have effectively changed consumption patterns and health. Crucially the divergence here is from our previous rather lonely and demonstrably ineffectual, although well meaning, professional reliance on 'telling' patients and attempting to motivate them to modify their diets. At least one speaker at the Summit declared himself optimistic about the future, and after so many years feeling that this was a war never to be won I do now believe that we have the beginnings of something rather positive.

There are many caveats to this optimism.

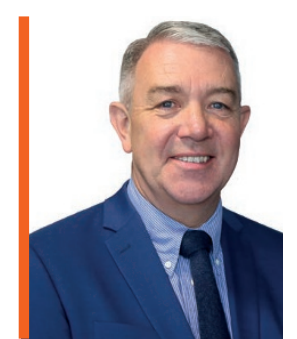

\section{'Soft drinks are only one element, how to progress the sugar tax to food?'}

based data, and acted upon by government and the food industry, has been calculated to have saved thousands of lives through lower blood pressure, a reduction in strokes and so forth. Seemingly we have all directly benefited from a reduction of which we are not generally aware.

So could a similar thing happen with sugar? Possibly in the longer term. The tax on soft drinks commencing in April 2018 has had a variety of effects. Some money has been raised by it (which may in due course increase and be directed towards health spending), consumption of the drinks with higher levels of sugar has fallen, and, most interestingly, many manufacturers have chosen to reformulate their products with lower levels of sugar to avoid the tax threshold. Taste-wise has anyone
Soft drinks are only one element, how to progress the sugar tax to food? The food industry is vast with seemingly bottomless pockets for marketing, legal action and political lobbying. We should certainly not abandon our individual and collective approaches to oral health education including dietary advice. We should also use all tools at our disposal too in terms of those same parameters of marketing, legal challenge (human rights to health being a pertinent example highlighted on the day) and political persuasion informed by evidence. An exciting boost created by an inspired day; well done BDA.

DOI: 10.1038/sj.bdj.2018.1041

1. Hancocks S. We are what others eat. Br Dent J 2017; 222: 907. 